\title{
Sedentary behavior and prevalence of obesity among Nepalese middle aged adults
}

\begin{abstract}
Sedentary behaviour and obesity is a major risk factor of non-communicable diseases among adult population. A descriptive cross-sectional research design was used to identify the sedentary behaviour and prevalence of obesity among Nepalese middle aged adults. Non- probability purposive sampling technique was used for the selection of 72 middle aged adults of Ward No. 25 of Kathmandu Metropolitan City, Nepal. Data collection was done from 18th to 30th September of 2016 by using structured interview schedule. Obtained data were edited, coded, classified manually and data entry and analysis were done using SPSS software version 16. Descriptive statistics and inferential statistics namely Chi square test were used to analyze the association between variables and the findings were presented on the relevant tables. The findings of this study revealed that the respondents have low $(23.6 \%)$, average $(37.5 \%)$ and high $(38.9 \%)$ sedentary behavior. Moreover, this study also revealed that 38.9 percent of respondents had normal weight, 47.2percent of them were overweight and least of them $(13.9 \%)$ were obese. Moreover, there is a significant association between sedentary behaviour and obesity and there is no association of age group, gender, ethnicity, educational status and type of occupation with overweight and obesity as well as with sedentary behavior. Based on the findings of this study, it is concluded that more than one third of middle aged adults have nearly equally average and high sedentary behaviour. Sedentary behavior of middle aged adults is associated with overweight and obesity. Therefore, it is recommended that the authority of Kathmandu Metropolitan City should conduct awareness programme regarding consequences of sedentary behaviour and obesity for the prevention of chronic non-communicable disease.
\end{abstract}

Keywords: sedentary behaviour, obesity, middle aged adults, metabolic syndrome
Volume I Issue 4 - 2017

\author{
Shristy Maharjan,' Rekha Timalsina² \\ 'Graduated from Lalitpur Nursing Campus, Nepal \\ ${ }^{2}$ Lecturer, Lalitpur Nursing Campus, Nepal
}

Correspondence: Rekha Timalsina, Lalitpur Nursing Campus, Nepal,Tel 0I-552I634, Fax +977-I-5529476,

Email rekha.timalsina@gmail.com

Received: April 29, 2017| Published: June 19, 2017

\section{Introduction}

Sedentary behaviour refers to any waking behaviour characterized by a low expenditure of energy while in a sitting or reclining posture. It mainly includes sitting or lying down while watching television or playing electronic games; sitting while at work or school, sitting while socializing with friends or family, sitting in a car or other form of motorized transport, sitting or lying down to read, working at a desk, and sitting and using a computer or mobile device., ${ }^{2,3}$ It is categorized as $\geq 35$ hours per week as high sedentary group, 20-34hours per week as average sedentary group and $\leq 19$ hours per week as low sedentary group. ${ }^{4}$ Sedentary lifestyle is related with urbanization. ${ }^{5}$ A study done in peri-urban Jhaukhel-Duwakot in Nepal revealed a high burden of physical inactivity with $43.3 \%$ prevalence of low physical activity. ${ }^{6}$ Sedentary behaviour may cause visceral obesity, type 2 diabetes and metabolic syndrome, weaker immune system, less executive control of the central nervous system; memory decline, sarcopenia and loss of strength, reduced skin-wound healing, lower oxidative capacity, higher risk of Alzheimer's disease, dementia, depression and anxiety etc. $^{7}$

Abnormal or excessive fats accumulation that may impair health are called overweight and obesity. Worldwide obesity has more than doubled since 1980; 39 percent of adults aged 18 years and over were overweight in 2014, and $13 \%$ were obese. ${ }^{8}$ Worldwide, at least 2.8 million people die each year as a result of being overweight or obese, and an estimated 35.8 million (2.3\%) of global disability adjusted life years (DALYs) are caused by overweight or obesity. ${ }^{9}$ Obesity is also associated with poorer mental health outcomes, reduced quality of life, and the leading causes of death worldwide It is also associated with diabetes, heart disease, stroke, and some types of cancer. ${ }^{9,10} \mathrm{Nepal}$ is one of the developing countries that is facing the consequences of potentially increasing obesity. ${ }^{5}$ Among civil servant in Nepal, prevalence of overweight/obesity was 33.4\%. ${ }^{11}$ Although sedentary behavior and obesity might cause non-communicable diseases, based on the available printed and published literature, research related to sedentary behavior and obesity appeared to be limited in Nepal. Therefore, the researcher had initiated an attempt to identify the sedentary behaviour and prevalence of obesity among middle aged adults. This will help to make aware for middle aged population about their sedentary behaviour and obesity and will help to improve their healthy lifestyles.

\section{Materials and methods}

A cross-sectional descriptive study design was used to identify sedentary behaviour and prevalence of obesity among Nepalese middle aged adults. The setting of the study was selected purposively and the study was done at Yetkha Tole, ward no.25 of Kathmandu Metropolitan city of Nepal near Hanuman-Dhoka Durbar Square. Non-probability purposive sampling technique was used to select sample of 72 middle aged adults. Middle aged adults aged 40-59 years and who had been living at this place of residence for at least 6 months were included as a sample and those people who were unable to hear and speak and unable to give response were excluded from this study. 
The instruments were divided into 2 parts: Part I: Information related to socio- demographic characteristics and anthropometric measurement of middle aged adults and Part II: Information related to sedentary behaviour that was spent sitting average weekly including working days and weekend: watching television; computer or internet use; reading newspaper; communicating with peers; travelling in a vehicle; day time sleeping and doing official work by sitting. In this study, sedentary behavior of middle aged adults was categorized as: Low sedentary behaviour: $\leq 19 \mathrm{hr}$ per week, Average sedentary behaviour: 20-34 hr per week and High sedentary behaviour: $\geq 35 \mathrm{hr}$ per week. ${ }^{4}$ Scoring Criteria of Body Mass Index (BMI) was categorized as Normal: BMI $\left(18.5-24.9 \mathrm{~kg} / \mathrm{m}^{2}\right)$, Overweight, BMI $\left(25-29.9 \mathrm{~kg} / \mathrm{m}^{2}\right)$ and Obese: $\mathrm{BMI}\left(\geq 30 \mathrm{~kg} / \mathrm{m}^{2}\right) .{ }^{9}$

The content validity of the instrument was established by reviewing related literatures and consulting with advisors, subject experts, and faculty members. The instrument was developed in English language and then, backward and forward translation of this instrument was done to identify the conceptual, linguistic and semantic equivalence of translated instrument. The translated Nepali version instrument was pretested among 10\% i.e., 7 middle aged adults in Teku, ward no. 9 who were similar in characteristics with actual sample of this study.

Formal administrative approval was taken from Campus Chief of Lalitpur Nursing Campus and the authority of Makhan Tole, ward no. 25, Kathmandu Metropolitan for conducting this study. Verbal informed consent was taken from each respondent by using informed consent form. Privacy was maintained by taking the interview separately away from the family members and by keeping the collected information confidential. For ensuring confidentiality, the respondent was assured that the respondent's identity was accessible only to the researcher and for research purpose only. Anonymity was assured by not writing their name in the interview schedule.

By considering above mentioned ethical consideration, the researcher collected data. The duration of data collection was 2 weeks started from 2nd Ashwin and end at 14th Ashwin, 2073 (September 18 to September 30, 2016) in Kathmandu Metropolitan city of Yetkha Tole, Ward no. 25. Structured interview schedule was used to collect data from the respondents regarding socio-demographic information, anthropometric measurement and sedentary behaviour among middle aged adults. Measurement device i.e., measuring tape was used for measuring height and weighing scale was used for measuring weight. Weight was measured in light clothing without shoes. The weighing scale was standardized to 0 scales before use. Standing height was measured with respondents in barefoot, back square against the wall and eyes looking straight ahead using the measuring tape and scale. After taking anthropometric measurement, a face-to-face interview was conducted with the respondents. Data were collected from each respondent within 30 minutes time including 5 minutes for measurement of height and weight.

The collected data was checked, reviewed and organized daily by the researcher for its completeness and accuracy. The collected data was edited, classified, coded manually. Then, data entry and data cleaning was done using SPSS 16 version. Descriptive statistics was used for describing the sample characteristics and chi-square test was used for identifying the association of sociodemographic characteristics with sedentary beahviour and obesity, For each test, significance was considered at $\mathrm{p}=\leq .05$ for $95 \%$ confidence interval.

\section{Results}

Among 72 respondents, 26.4 percent of respondents were belonged to age group of 55-60years. Mean age of the respondents was 56.64 years with SD 5.24 and the age group ranged from 40years to 58years. Majority of the respondents $(62.5 \%)$ were Newar and least respondents (2.8\%) were Tamang. More than two-third of respondents $(79.2 \%)$ were literate. Similarly, 86.1 percent of respondents were staying in nuclear family. Most of the respondents (93.1\%) were married whereas least respondents $(2.8 \%)$ had divorced. More than half of respondents $(54.2 \%)$ were involved in business followed by house maker, service and agriculture (Table 1). Table 2 shows that the respondents have nearly equally average $27(37.5 \%)$ and high $28(38.9 \%)$ level of sedentary behavior. Table 3 shows that more than one-third of respondents $28(38.9 \%)$ were overweight and only $10(13.9 \%)$ respondents were obese. Table 4 displays that there is a significant association between sedentary behavior, and overweight and obesity $\left(\mathrm{X}^{2}=6.726, \mathrm{p}=0.035\right)$. However, there is no significant association of age group, gender, ethnicity, educational status, occupation with overweight and obesity. Table 5 shows that there is no association between sociodemographic characteristics and sedentary behavior.

Table I Socio-Demographic Characteristics of the Respondents

\begin{tabular}{|c|c|c|}
\hline Characteristics & Frequency & Percent \\
\hline \multicolumn{3}{|l|}{ Age } \\
\hline $40-45$ & 18 & 25 \\
\hline $45-50$ & 17 & 23.6 \\
\hline $50-55$ & 18 & 25 \\
\hline $55-60$ & 19 & 26.4 \\
\hline Mean age in years \pm SD & $50.64 \pm 5.247$ & \\
\hline \multicolumn{3}{|l|}{ Gender } \\
\hline Male & 39 & 54.2 \\
\hline Female & 33 & 45.8 \\
\hline \multicolumn{3}{|l|}{ Ethnicity } \\
\hline Newar & 45 & 62.5 \\
\hline Brahmin & 16 & 22.2 \\
\hline Chhetri & 9 & 12.5 \\
\hline Tamang & 2 & 2.8 \\
\hline \multicolumn{3}{|l|}{ Educational Status } \\
\hline Literate & 57 & 79.2 \\
\hline Illiterate & 15 & 20.8 \\
\hline \multicolumn{3}{|l|}{ Types of Family } \\
\hline Nuclear & 62 & 86.1 \\
\hline Joint & 7 & 9.7 \\
\hline Extended & 3 & 4.2 \\
\hline \multicolumn{3}{|l|}{ Marital Status } \\
\hline Married & 67 & 93.1 \\
\hline Unmarried & 3 & 4.2 \\
\hline Divorced & 2 & 2.8 \\
\hline \multicolumn{3}{|l|}{ Occupational Status } \\
\hline Business & 39 & 54.2 \\
\hline House maker & 18 & 25 \\
\hline Service & 8 & 11.1 \\
\hline Agriculture & 7 & 9.7 \\
\hline
\end{tabular}


Table 2 Level of Sedentary Behaviour among Respondent's

\begin{tabular}{lll}
\hline Sedentary behaviour & Frequency & Percent \\
\hline Low Sedentary Behaviour & 17 & 23.6 \\
Average Sedentary Behaviour & 27 & 37.5 \\
High Sedentary Behaviour & 28 & 38.9
\end{tabular}

Note Low sedentary behaviour, $\leq 19 \mathrm{hr}$ per week, Average sedentary behaviour, 20-34hr per week \& high sedentary behaviour $\geq 35 \mathrm{hr}$ per week.
Table 3 Body Mass Index of Respondent's

\begin{tabular}{lll}
\hline Body mass index (BMI) & Frequency & Percent \\
\hline Normal & 28 & 38.9 \\
Overweight & 34 & 47.2 \\
Obese & 10 & 13.9 \\
\hline
\end{tabular}

Note Normal, BMI $\left(18.5-24.9 \mathrm{~kg} / \mathrm{m}^{2}\right)$, Overweight, BMI $\left(25-29.9 \mathrm{~kg} / \mathrm{m}^{2}\right)$, and Obese, BMI $\left(\geq 30 \mathrm{~kg} / \mathrm{m}^{2}\right)^{7}(\mathrm{WHO}, 2016 \mathrm{a})$

Table 4 Association of Sociodemographic Characteristics and Sedentary Behaviour with Overweight and Obesity of Respondents

\begin{tabular}{|c|c|c|c|c|c|c|}
\hline \multirow[t]{3}{*}{ Characteristics } & \multicolumn{3}{|c|}{ Overweight and Obesity } & \multirow[b]{3}{*}{ (\%) } & \multirow[t]{3}{*}{$X^{2}$ value } & \multirow[t]{3}{*}{ p-value } \\
\hline & \multicolumn{2}{|c|}{ Absent } & \multirow{2}{*}{$\begin{array}{l}\text { Present } \\
\mathbf{N}\end{array}$} & & & \\
\hline & $\mathbf{N}$ & $(\%)$ & & & & \\
\hline \multicolumn{7}{|l|}{ Age Group } \\
\hline$\leq 50$ & 17 & 48.6 & 18 & 51.4 & & \\
\hline$\geq 50$ & II & 29.7 & 26 & 70.3 & 2.687 & 0.101 \\
\hline \multicolumn{7}{|l|}{ Gender } \\
\hline Male & 17 & 43.6 & 22 & 56.4 & & \\
\hline Female & II & 33.3 & 22 & 66.7 & 0.791 & 0.374 \\
\hline \multicolumn{7}{|l|}{ Ethnicity } \\
\hline Bramhin and Chhetri & 12 & 48 & 13 & 52 & & \\
\hline Newar and Others & 16 & 34 & 31 & 66 & 1.338 & 0.247 \\
\hline \multicolumn{7}{|l|}{ Educational Status } \\
\hline Illiterate & 21 & 36.8 & 36 & 63.2 & 0.482 & 0.487 \\
\hline Literate & 7 & 46.7 & 8 & 53.3 & & \\
\hline \multicolumn{7}{|l|}{ Occupation } \\
\hline Agriculture Business and Service Holder & 21 & 38.9 & 33 & 61.1 & & \\
\hline Homemaker & 7 & 38.9 & 11 & 61.1 & 0 & 1 \\
\hline \multicolumn{7}{|l|}{ Sedentary Behaviour } \\
\hline Low & II & 64.7 & 6 & 35.3 & & \\
\hline Average & 7 & 29.2 & 17 & 70.8 & & \\
\hline High & 8 & 29.6 & 19 & 70.4 & 6.726 & $0.035^{*}$ \\
\hline
\end{tabular}

Note ${ }^{*} \mathrm{p} \leq .05$, Significant at $95 \%$ Confidence Interval. Overweight and Obesity, Aggregate of overweight and Obesity

Table 5 Association between Sociodemographic Characteristics and Sedentary Behaviour of Respondents

\begin{tabular}{|c|c|c|c|c|c|c|c|c|}
\hline \multirow[t]{3}{*}{ Characteristics } & \multicolumn{6}{|c|}{ Sedentary Behaviour } & \multirow[t]{3}{*}{$X^{2}$ value } & \multirow[t]{3}{*}{ p-value } \\
\hline & \multicolumn{2}{|c|}{ Low } & \multicolumn{2}{|l|}{ Average } & \multicolumn{2}{|l|}{ High } & & \\
\hline & $\mathbf{N}$ & (\%) & $\mathbf{N}$ & (\%) & $\mathbf{N}$ & (\%) & & \\
\hline \multicolumn{9}{|l|}{ Age } \\
\hline$<50$ Years & 7 & 21.2 & 11 & 33.3 & 15 & 45.5 & 0.971 & 0.615 \\
\hline$>50$ Years & 10 & 28.6 & 13 & 37.1 & 12 & 34.3 & & \\
\hline \multicolumn{9}{|l|}{ Gender } \\
\hline Male & 9 & 25 & 15 & 41.7 & 12 & 33.3 & & \\
\hline Female & 8 & 25 & 9 & 28.1 & 15 & 46.9 & 1.663 & 0.435 \\
\hline
\end{tabular}

Citation: Maharjan S,Timalsina R. Sedentary behavior and prevalence of obesity among Nepalese middle aged adults. MOJ Gerontol Ger. 20 I 7; I (4): I05-I09. DOI: I0.15406/mojgg.20I7.01.00023 
Table Continued....

\begin{tabular}{|c|c|c|c|c|c|c|c|c|}
\hline \multirow[t]{3}{*}{ Characteristics } & \multicolumn{6}{|c|}{ Sedentary Behaviour } & \multirow[t]{3}{*}{$X^{2}$ value } & \multirow[t]{3}{*}{ p-value } \\
\hline & \multicolumn{2}{|c|}{ Low } & \multicolumn{2}{|l|}{ Average } & \multicolumn{2}{|l|}{ High } & & \\
\hline & $\mathbf{N}$ & $(\%)$ & $\mathbf{N}$ & (\%) & $\mathbf{N}$ & (\%) & & \\
\hline \multicolumn{9}{|l|}{ Ethnicity } \\
\hline Bramhin and Chhetri & 9 & 36 & 9 & 36 & 7 & 28 & & \\
\hline Newar and Others & 8 & 18.6 & 15 & 34.9 & 20 & 46.5 & 3.283 & 0.194 \\
\hline \multicolumn{9}{|l|}{ Educational Status } \\
\hline Illiterate & II & 20.8 & 18 & 34 & 24 & 45.3 & 3.735 & 0.155 \\
\hline Literate & 6 & 40 & 6 & 40 & 3 & 20 & & \\
\hline \multicolumn{9}{|l|}{ Occupation } \\
\hline Agriculture, Business and Service & 10 & 19.6 & 19 & 37.3 & 22 & 43.1 & 3.2 & 0.202 \\
\hline Homemaker & 7 & 41.2 & 5 & 29.4 & 5 & 29.4 & & \\
\hline
\end{tabular}

\section{Discussion}

The current study was conducted asking respondents to report average weekly (i.e., during workdays and weekend) time that was spent on sitting by: (1) watching television; (2) computer or internet use; (3) reading newspaper; (4) communicating with peers; (5) travelling in vehicles; (6) day time sleeping and (7) doing official work by sitting.

The current study revealed that less than one-third of respondents $(23.6 \%)$ spent low levels of sedentary behavior and more than one third of respondents had nearly equally average (37.5\%) and high levels of sedentary behavior (38.9\%). This finding is different with the study conducted among adults in Canada which concluded that more than one-third of the sample (39\%) reported low levels of sedentary behaviour per week. ${ }^{4}$ Even though, there is difference in proportion of low level of sedentary behavior in different geographical settings either in Canada or Nepal, these findings may suggest that the sedentary behavior is prevalent among adult population.

The present study has yielded that more than one-third of respondents $34(47.2 \%)$ were overweight and only $10(13.9 \%)$ respondents were obese which is different to the study conducted in rural South India where the overall prevalence of overweight and obesity was documented to be $14.9 \%$ and $19.4 \%$ respectively. ${ }^{12}$ Similarly, a study conducted in Malaysia revealed that the overall prevalence of overweight and obesity were found to be $33.6 \%$ and $19.5 \%$ which is different from the current study. ${ }^{13}$ Yet another previous study conducted in United States revealed that the prevalence of obesity was higher among middle aged adults $40.2 \% .{ }^{14}$ The current and previous study findings revealed that overweight and obesity is prevalent among adult population.

The present study reported that there is a significant association between sedentary behavior, and overweight and obesity $\left(\mathrm{X}^{2}=6.726\right.$, $\mathrm{p}=0.035$ ), which is different to the study conducted in Canada which revealed that the time spent in sedentary behaviour did not predict future obesity. ${ }^{15} \mathrm{TV}$ viewing is one of the sedentary behavior that was most consistently associated with adiposity markers in adults. ${ }^{16}$ However, there is no significant association of age group, gender, ethnicity, educational status, occupation with overweight and obesity. A previous study conducted in India revealed the prevalence of obesity was distinctively higher among females as compared to the males $(29.33 \%$ versus $9.67 \%)$. This study further revealed that sex and age also showed significant effects with combined overweightobesity. ${ }^{17}$

A current study reveals that there is no association between sociodemographic characteristics (i.e., age group, gender, ethnicity, educational status, occupation) and sedentary behavior. A previous study in Malaysia showed that age, ethnicity, occupational status, marital status and diabetes were likely to be predictors of being sedentary. ${ }^{13}$ These differences might be related to differences in sample size and geographical location.

\section{Conclusion}

Based on the findings of this study, it is concluded that more than one third of middle aged adults have nearly equally average and high sedentary behaviour. Similarly, nearly half of middle aged adults residing in Yetkha Tole, Ward No. 25 of Kathmandu Metropolitan City, Nepal had overweight and less than one fifth of them had obesity.

Sedentary behavior is associated with overweight and obesity. Therefore, awareness programme regarding sedentary behavior and prevalence of obesity with its consequences should be organized by the authority which helps to decrease health problems i.e., chronic non-communicable disease like diabetes, hypertension, cancer etc. and increase the quality of life of middle aged adult which ultimately helps to live comfortably in later life.

The limitation of this study is: the respondents were asked questions about their time spent in past weekdays and weekend. Therefore, there may have a chance of recall bias or memory bias because it is difficult to respondents to recall the average duration spent on sitting in past 7 days. Another limitation is: sitting time was quantified based on selfreport that might be subjected to measurement error. Respondents may under or over stated their sitting time excessively.

\section{Acknowledgements}

It is our pleasure to express our sincere thanks to Campus Chief Professor Sarala K.C., Assistant Campus Chief Professor Ambika Poudel, and all the faculty members of Lalitpur Nursing Campus. Our sincere thanks go to the authority of Yetkha Tole, ward no. 25 of Kathmandu Metropolitan city for giving us permission for data collection. We are very thankful for the respondents who had given their valuable time and response. Without their co-operation and support, the study wouldn't have been possible to complete. 


\section{Conflict of interest}

Authors declare there is no conflict of interest in publishing the article.

\section{References}

1. Sedentary Behaviour Research, Network. Letter to the editor: Standardized use of the terms "sedentary" and "sedentary behaviours. Applied Physiology, Nutrition, and Metabolism, 2012;37(3):540-542.

2. British Heart Foundation National Centre (BHFNC) for Physical Activity and Health. What is sedentary behavior; 2012.

3. Australian National Preventive Health Agency. Obesity: Sedentary behaviours and health. 2014. CL, Copeland JL. Sedentary behaviour among adults: The role of community belonging. Preventive Medicine Reports. 2016;89(3):45-49.

4. Vaidya A, Shakya S, Krettek A. Obesity prevalence in Nepal: Public health challenges in a low-income nation during an alarming worldwide trend. International Journal of Environmental Science. 2010;7(6)2726-2744.

5. Vaidya A, Krittek A. Physical activity level and its sociodemographic correlates in a peri-urban Nepalese population: A cross-sectional study from the Jhaukhel-Duwakot health demographic surveillance site International Journal of Behavioral Nutrition and Physical Activity. 2014;11(39):233-236.

6. Morton GA, Kravitz L. Major consequences of physical inactivity; 2016.

7. World Health Organization. Obesity and overweight; $2016 a$.
8. World Health Organization. Obesity: Situations and trends; 2016b.

9. Center for Disease Control and Prevention. Adult obesity causes \& consequences; 2016.

10. Simkhada P, Poobalan A, Simkhada PP, et al. Knowledge, attitude, and prevalence of overweight and obesity among civil servants in Nepal. Asia-Pacific Journal of Public Healt. 2011;23(4):507-517.

11. Little M, Humphries S, Patel K, et al. Factors associated with body mass index, underweight, overweight and obesity among adults in a population of rural South India. British Medical Journal of Obesity. 2016;7(18):437-445

12. Jamil AT, Rosli NM, Ismail A, et al. Prevalence and risk factors for sedentary behavior among Malaysian adults. Malaysian Journal of Public Health Medicine. 2016;16(3):147-155.

13. Ogden CL, Carrol MD, Frayar CD, et al. Prevalence of obesity among adults and youth: United States, 2011-2014. National Centre of Health Statistics Data Brief. 2015;219:1-8.

14. Ekelund U, Brage S, Besson H, et al. Time spent being sedentary and weight gain in healthy adults: Reverse or bidirectional causality. American Journal of Clinical Nutrition, 2008;88(3):612-617.

15. Heinonen I, Helajarvi H, Pahkala K, et al. Sedentary behaviours and obesity in adults: The cardiovascular risk in young Finns study. British Medical Journal Open. 2013;3(6):e00290.

16. Sen J, Mondal N, Dutta S. Factors affecting overweight and obesity among urban adults: A cross-sectional study. Epidemiology Biostatistics and Public health. 2013;10(1):456-460. 